\title{
Overexpression of HMGAI promotes anoikis resistance and constitutive Akt activation in pancreatic adenocarcinoma cells
}

\author{
S-S Liau', A Jazag', K Ito' and EE Whang*,I \\ 'Department of Surgery, Brigham and Women's Hospital, Harvard Medical School, 75 Francis Street, Boston, MA 02I I5, USA
}

\begin{abstract}
HMGA I proteins are architectural transcription factors that are overexpressed by pancreatic adenocarcinomas. Roles of HMGAI in mediating the malignant phenotype of this cancer are poorly understood. We tested the hypothesis that overexpression of HMGA I promotes resistance to anoikis (apoptosis induced by anchorage deprivation) in pancreatic cancer cells. HMGAI cDNA was stably transfected into MiaPaCa2 human pancreatic adenocarcinoma cells (which have low baseline expression levels of HMGAI). Cells were grown in suspension on PolyHEMA-coated plates and their susceptibility to anoikis was assayed using flow cytometry. Overexpression of HMGAI was associated with marked reductions in susceptibility to anoikis in concert with increases in Akt phosphorylation (Ser473) and in Akt kinase activity and with reductions in caspase 3 activation. Inhibition of phosphoinositidyl-3 (PI3K)/Akt pathway with either the small molecule inhibitor LY294002 or dominant-negative Akt resulted in reversal of anoikis resistance induced by HMGAI overexpression. Further, RNA interference-mediated HMGAI silencing in MiaPaCa2 and BxPC3 (a human pancreatic adenocarcinoma cell line with high baseline levels of HMGAI expression) cells resulted in significant increases in susceptibility to anoikis. Our findings suggest HMGAI promotes anoikis resistance through a PI3-K/Akt-dependent mechanism. Given the putative associations between anoikis resistance and metastatic potential, HMGAI represents a potential therapeutic target in pancreatic adenocarcinoma.
\end{abstract}

British Journal of Cancer (2007) 96, 993-1000. doi:I0.I038/sj.bjc.6603654 www.bjcancer.com

Published online 6 March 2007

(C) 2007 Cancer Research UK

Keywords: HMGAI; Akt; anoikis; pancreatic adenocarcinoma

Pancreatic adenocarcinoma is among the deadliest of all human cancers, with 5 -year survival rates averaging less than 5\% (Jemal et al, 2006). The propensity for pancreatic adenocarcinoma cells to metastasise early in the course of disease progression makes this cancer particularly refractory to standard therapies. Characterising the underlying mechanisms mediating metastatic dissemination in pancreatic adenocarcinoma may reveal novel targets for inhibiting this process, which is so aggressive in this cancer.

Anoikis, derived from a Greek word meaning 'homelessness', was used in describing the observation that depriving cells from attachment to matrix triggers apoptosis in these cells (Frisch and Francis, 1994). Increasingly, metastasis is conceptualised to be a multistep process facilitated by the evolution of anoikis-resistant subsets of cancer cells that are capable of surviving in the blood stream during dissemination after they detach from the primary tumour and its stroma. Indeed, numerous studies suggest a close correlation between signalling events mediating cellular anoikis resistance in vitro and those mediating metastatic potential in vivo (Yawata et al, 1998; Zhu et al, 2001; Douma et al, 2004; Berezovskaya et al, 2005).

The human HMGA1 gene, located on chromosomal locus $6 \mathrm{p} 21$, encodes two HMGAl splice variants (HMGAla and HMGA1b) (Friedmann et al, 1993). These HMGA1 proteins are architectural

\footnotetext{
*Correspondence: Dr EE Whang, E-mail: liauss@hotmail.com or ewhangl@partners.org

Received 23 October 2006; revised 21 December 2006; accepted 30 January 2007; published online 6 March 2007
}

transcription factors that regulate gene expression in vivo by forming stereo-specific, multiprotein complexes termed 'enhanceosomes' on the promoter regions of genes (Reeves and Nissen, 1990; Thanos and Maniatis, 1995). HMGA1 proteins are overexpressed in a range of human cancers, notably including pancreatic adenocarcinoma (Abe et al, 2000; Balcerczak et al, 2003; Chiappetta et al, 2004; Czyz et al, 2004; Donato et al, 2004; Chang et al, 2005; Sarhadi et al, 2006; Xu et al, 2004). Moreover, high tumoural expression of HMGA1 has been reported to be predictive of poor prognosis among patients with cancer (Tamimi et al, 1996; Balcerczak et al, 2003; Chiappetta et al, 2004).

Although these correlative data suggest a potential role for HMGA1 in cancer pathogenesis, the underlying biology of HMGA1 in the context of cancer progression is poorly understood. The purpose of this study was to test the hypothesis that HMGA1 promotes anoikis resistance in pancreatic adenocarcinoma. Our observations indicate that HMGA1 promotes anoikis resistance through the phosphoinositidyl-3 kinase (PI3-K)/Akt pathway.

\section{MATERIALS AND METHODS}

\section{Cells and cell culture}

MiaPaCa2 and BxPC3 human pancreatic ductal adenocarcinoma cells were obtained from American Type Culture Collection (ATCC; Manassas, VA, USA). Cells were maintained in DMEM containing $10 \%$ fetal bovine serum (FBS) (Gibco Life Technologies Inc., Gaithersburg, MD, USA) and incubated in a humidified 
$\left(37^{\circ} \mathrm{C}, 5 \% \mathrm{CO}_{2}\right)$ incubator, grown in $75-\mathrm{cm}^{2}$ culture flasks, and passaged on reaching $80 \%$ confluence.

\section{Reagents and dominant-negative Akt adenovirus}

The PI3-K-inhibitor LY294002 was purchased from Calbiochem (San Diego, CA, USA). Anti-HMGA1, anti-lamin B and anti-Akt antibodies were obtained from Santa Cruz Biotechnology (Santa Cruz, CA, USA). Anti-phospho Akt (ser473) antibody was obtained from Cell Signaling Technology (Danvers, MA, USA). Adenovirus expressing dominant-negative murine Akt1 and control virus (Ad-CMV-null) (both titred at $1 \times 10^{10} \mathrm{PFU} \mathrm{ml}^{-1}$ ) were purchased from Vector Biolabs (Philadelphia, PA, USA). Adenoviral infection was performed at multiplicity of infection of 10 in the presence of $6 \mu \mathrm{g} \mathrm{ml}^{-1}$ polybrene for $12 \mathrm{~h}$. Experiments were performed on cells $48 \mathrm{~h}$ following infection.

\section{Expression vector and transfection}

The HMGA1-coding sequence was PCR amplified from IMAGE clone 5399570 (GenBank accession no. BC063434) using genespecific primers modified to include the appropriate restriction sites at their $5^{\prime}$ end. The primers used were: forward, 5' TTTTGATATCATGAGTGAGTCGAGCTCGAAG- $3^{\prime}$ and backward, $5^{\prime}$-TTTTGAATTCTCACTGCTCCTCCTCCGAGGA-3'. Purified PCR products were digested with EcoRV and EcoRI, before ligation into a EcoRV/EcoRI-digested pIRES-puro3 vector (Clontech, Palo Alto, CA, USA). The expression plasmid was named pIRES-HMGA1. $\mathrm{MiaPaCa} 2$ cells were transfected with pIRES-HMGA1 or empty pIRES-puro3, which acted as a control, using Lipofectamine 2000 (Invitrogen, Carlsbad, CA, USA) in accordance with the manufacturer's protocol. Stable clones were selected by exposure to incrementally increasing concentrations of puromycin (Invivogen, San Diego, CA, USA), isolated using cloning cylinders and maintained in medium containing $3 \mu \mathrm{g} \mathrm{ml}^{-1}$ puromycin (Invivogen). Clones pIRES-HMGA1.1 and pIRES-HMGA1.2, which expressed the highest levels of HMGA1, were used for further studies.

\section{Lentivirus-mediated HMGA1 RNAi}

Lentiviral hairpin RNA interference (RNAi) plasmids (pLKO.1HMGA1, TRCN0000018949), constructed as described previously (Stewart et al, 2003), were obtained from the RNAi Consortium (Mission TRC Hs. 1.0, Sigma Aldrich, St Louis, MO, USA). The sequence of short hairpin RNA (shRNA) targeting the human HMGA1 gene (GenBank accession no. NM_002131) was $5^{\prime}$-AACTCCAGGAAGGAAACCAA- $3^{\prime}$, corresponding to the coding region positions 446-466. The controls were lentiviral particles produced with empty pLKO.1 and pLKO.1, which has a scramble nontargeting shRNA sequence obtained from Addgene (Cambridge, MA, USA), deposited by Dr David Sabatini (Sarbassov et al, 2005). Each of these vectors had been sequence-verified. Vectors were expanded in chemically competent Escherichia coli (TOP10 cells, Invitrogen) and purified using Genelute maxiprep kit (Sigma Aldrich). To generate lentiviral particles, human embryonic kidney 293 cells (ATCC) were cotransfected with the lentiviral vector and compatible packaging plasmid mixture (Virapower lentiviral packaging system, Invitrogen) using Lipofectamine 2000 (Invitrogen), in accordance to manufacturer's instruction. Pancreatic adenocarcinoma cells were exposed to lentivirus-containing supernatant for $16 \mathrm{~h}$ in the presence of $6 \mu \mathrm{g} \mathrm{ml}^{-1}$ polybrene (Sigma, St Louis, MI, USA). Pooled stable transfectants were established using puromycin selection. Stable transfectant cells were maintained in medium containing $3 \mu \mathrm{g} \mathrm{ml}^{-1}$ of puromycin (Invivogen).

\section{Anoikis induction and flow cytometry}

Anoikis was assayed by plating cells on polyHEMA-coated plates. A solution of $120 \mathrm{mg} \mathrm{ml}^{-1}$ polyHEMA (Sigma) in $100 \%$ ethanol was made and diluted 1:10 in $95 \%$ ethanol; $0.95 \mathrm{ml} \mathrm{mm}^{-2}$ of this solution was overlaid onto $35-\mathrm{mm}$ wells and left to dry in a heated dryer system for $12 \mathrm{~h}$. Before use, wells were washed twice with PBS and once with DMEM. In all, $1 \times 10^{6}$ cells of each line, suspended in $2 \mathrm{ml}$ DMEM with $10 \%$ FBS were incubated in the polyHEMA-coated wells for $12-18 \mathrm{~h}$ in a humidified $\left(37^{\circ} \mathrm{C}, 5 \% \mathrm{CO}_{2}\right)$ incubator. Cells were harvested and resuspended in $0.3 \mathrm{ml}$ of PBS containing 2\% FBS and $0.1 \mu \mathrm{M}$ EDTA. Apoptosis staining was performed using $1 \mu \mathrm{lml}^{-1}$ YOPRO-1 and propidium iodide (Vybrant Apoptosis Assay Kit \#4; Molecular Probes, Eugene, OR, USA). Cells were incubated for $30 \mathrm{~min}$ on ice and then analysed by flow cytometry (FACScan; Becton Dickinson, Franklin Lakes, NJ, USA), measuring fluorescence emission at 530 and $575 \mathrm{~nm}$. Cells stained with the green fluorescent dye YO-PRO-1 were counted as apoptotic; necrotic cells were stained with propidium iodide. The number of apoptotic cells was divided by the total number of cells (minimum of $10^{4}$ cells), resulting in the apoptotic fraction. Data were analysed using CellQuest software (Becton Dickinson). All assays were performed in triplicates.

\section{Western blotting}

Cells were harvested and rinsed twice with PBS. Total cell extracts were prepared with lysis buffer (20 mm Tris, $\mathrm{pH} 7.5,0.1 \%$ Triton $\mathrm{X}$, $0.5 \%$ deoxycholate, $1 \mathrm{mM}$ PMSF, $10 \mathrm{mg} \mathrm{ml}^{-1}$, aprotinin, $10 \mathrm{mg} \mathrm{ml}^{-1}$ leupeptin) and cleared by centrifugation at $15000 \mathrm{~g}, 4^{\circ} \mathrm{C}$. Nuclear extracts were prepared using NE-PER nuclear and cytoplasmic extraction reagents based on the manufacturer's instruction (Pierce, Rockford, IL, USA). Total protein concentration was measured using the BCA assay kit (Sigma) with bovine serum albumin as a standard, according to the manufacturer's instructions. Total cell lysates containing $50 \mu \mathrm{g}$ total protein or nuclear protein containing $10 \mu \mathrm{g}$ total protein were subjected to $10 \%$ SDS/PAGE and the resolved proteins transferred electrophoretically to PVDF membranes (Invitrogen). Equal protein loading was confirmed by Coomassie (BioRad, Hercules, CA, USA) staining of the gel. After blocking with PBS containing 3\% bovine serum albumin for $1 \mathrm{~h}$ at room temperature, membranes were incubated with $3-5 \mathrm{mg} \mathrm{ml}^{-1}$ antibody in PBS containing $0.1 \%$ Tween-20 overnight at $4^{\circ} \mathrm{C}$. Chemoluminescensce detection (Amersham Biosciences, Piscataway, NJ, USA) was performed in accordance with the manufacturer's instructions. The densitometric signal was quantified using ImagePro Plus software version 4.0 (Media Cybernetics, Silver Spring, MD, USA) and normalised to that of loading control as appropriate. Blots were performed in triplicate in at least three independent experiments. Mean densitometric values $( \pm$ standard Deviation (s.d.)) are shown.

\section{Fluorometric real-time Akt kinase assay}

Assay was performed using the Omnia Lysate Akt kinase assay (Biosource-Invitrogen, Carlsbad, CA, USA), according to the manufacturer's instructions. Briefly, total cell lysate equivalent to $5 \mu \mathrm{g} \mu \mathrm{l}^{-1}$ was loaded into each well. Following addition of fluorescent Akt substrates and kinase buffer, fluorescent signal was acquired real-time (excitation, $360 \mathrm{~nm}$; emission, $485 \mathrm{~nm}$ ) for 60 min using SpectraMax M5 microplate reader (Molecular Devices, Sunnyvale, CA, USA). The Akt kinase activity was calculated from the slope of activity curve. Experiments were performed in triplicates on at least three occasions.

\section{Fluorometric caspase profiling}

Whole-cell lysates were assayed for caspases 3 activity using the BD ApoAlert Caspase Assay Plate (BD Biosciences Clontech, Palo 
Alto, CA, USA) according to the manufacturer's instructions. Plates were read (excitation, $360 \mathrm{~nm}$; emission, $480 \mathrm{~nm}$ ) using SpectraMax M5 microplate reader in fluorescence mode (Molecular Devices). All measurements were performed in triplicate, each with three determinations for each condition.

\section{Proliferation assay}

Cell proliferation was quantified using an MTS (3-(4,5 dimethylthiazol-2-yl)-5-(3-carboxymethoxyphenyl-2-(4-sulfophenyl)$2 \mathrm{H}$-tetrazolium) assay (CellTiter 96 Aqueous One Solution Assay, Promega, Madison, WI, USA), in accordance to the manufacturer's instructions and confirmed by cell counting. Logarithmically growing cells were seeded into 96-well plates at $5 \times 10^{3}$ cells per well and allowed to adhere overnight in medium containing $10 \%$ FBS. Cell proliferation was determined after $48 \mathrm{~h}$. Plates were read with the use of the SpectraMax M5 microplate spectrophotometer (Molecular Devices) at a wavelength of $490 \mathrm{~nm}$. Ten samples were used for each experimental condition and experiments were performed in triplicate. At identical time points, cell counting was performed. Cells were trypsinised to form a single-cell suspension. Viable cells, determined by trypan blue exclusion, were counted with the use of a Neubauer hemocytometer (Hausser Scientific, Horsham, PA, USA).

\section{Statistical analysis}

Differences between groups were analysed using Student's $t$-test, multifactorial ANOVA of initial measurements and MannWhitney $U$-test for nonparametric data, as appropriate, using Statistica 5.5 software (StatSoft Inc., Tulsa, OK, USA). In cases in which averages were normalised to controls, the s.d. of each nominator and denominator were taken into account in calculating the final s.d.. $P<0.05$ was considered statistically significant.

\section{RESULTS}

HMGA1 overexpression promotes anoikis resistance in MiaPaCa2 pancreatic adenocarcinoma cells

Stable overexpression of HMGA1 was achieved in MiaPaCa2 cells, which have low inherent expression levels of HMGA1. Two stable HMGA1-overexpressing clones were selected and named pIRESHMGA1.1 and pIRES-HMGA1.2. HMGA1 overexpression was confirmed on Western blot analysis (Figure 1). Levels of HMGA1 overexpression in pIRES-HMGA1.1 and pIRES-HMGA1.2 were four- and 3.5-fold higher than in control cells, respectively. There was no difference in the levels of HMGA1 expression between the empty pIRES-puro3 transfectants and parental MiaPaCa2 cells. Following $18 \mathrm{~h}$ of anchorage-deprivation (on polyHEMA plates), pIRES-HMGA1.1 and pIRES-HMGA1.2 clones showed significantly increased anoikis resistance (mean anoikis fractions of 11 and $13 \%$, respectively) when compared to controls (mean anoikis fractions for parental MiaPaCa2 and empty pIRES-puro3 transfectants were 26 and $27 \%$, respectively, Figure $2 \mathrm{~A}$ and $2 \mathrm{~B}$ ).

\section{HMGA1 overexpression results in protection from caspase- mediated apoptosis}

Given that disruption of cell-matrix interactions can trigger anoikis via caspase-dependent apoptosis, we examined the effects of HMGA1 overexpression on caspase 3 activity (a central mediator of apoptosis) in the context of anchorage deprivation. During induction of anoikis on polyHEMA plates, HMGA1overexpressing clones demonstrated markedly reduced levels of caspase 3 activity compared to parental MiaPaCa2 or pIRES-puro3 controls (Figure 2C).

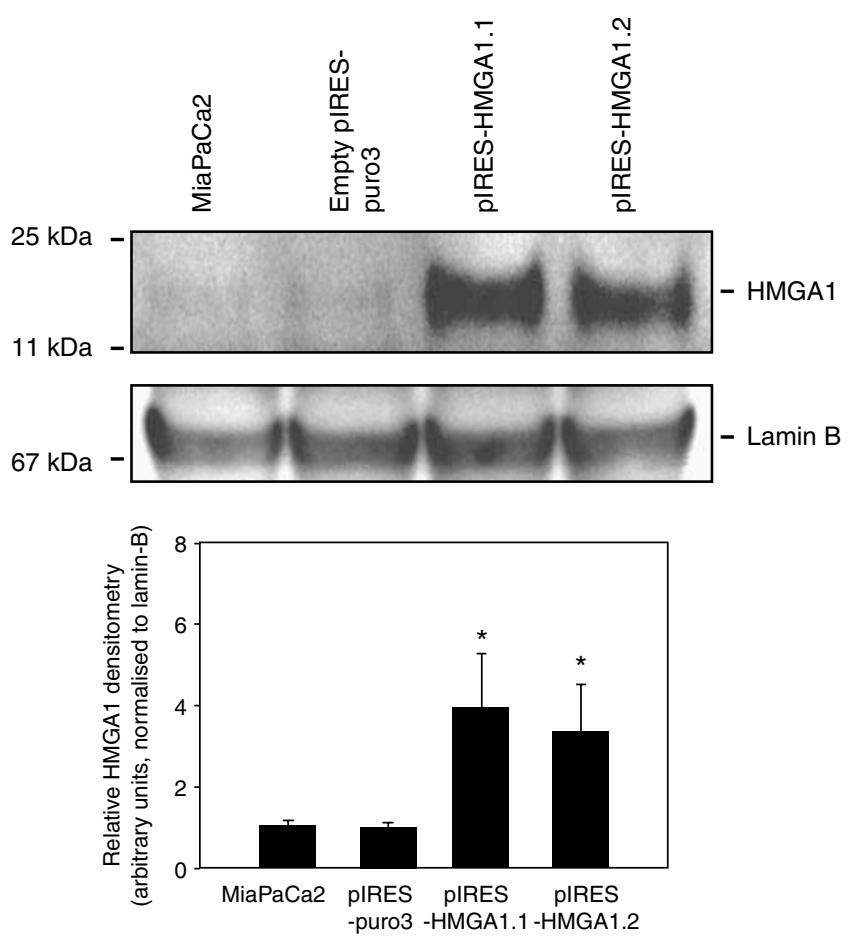

Figure I Two stable transfectant clones derived from MiaPaCa2 cells were confirmed to overexpress HMGAI (pIRES-HMGAI.I and I.2) on Western blot analysis of nuclear extracts. Lamin B was used as a loading control. Controls were parental MiaPaCa2 cells or cells stably transfected with empty pIRES-puro3 vector. *Blots shown are representative of three independent experiments. Densitometry values, normalised to Lamin B signals, are mean \pm s.d.. $P<0.05$ vs empty pIRES-puro3 vector and parental MiaPaCa2 cells.

\section{Overexpression of HMGA1 increases levels of Akt phosphorylation and Akt kinase activity}

PI3-K/Akt-signalling pathway is of critical importance in mediating anoikis resistance and enhancing anchorage-independent cell cycle progression (Moore et al, 1998; Nguyen et al, 2002). Given these observations, we sought to determine if HMGA1 overexpression would modulate Akt phosphorylation at Ser473, a marker of Akt activation. HMGA1 overexpression resulted in elevated Akt (Ser473) phosphorylation (Figure 3A). Consistent with this finding, HMGA1 overexpression was found to be associated with increases in Akt kinase activity (Figure 3B).

\section{Inhibition of Pl3-K/Akt signalling reverses HMGA1 overexpression-induced anoikis resistance}

Having demonstrated that HMGA1 overexpression induces constitutive activation of PI3-K/Akt pathway, we next examined the effects of inhibiting this pathway in cells overexpressing HMGA1. First, we used a specific small molecule inhibitor of PI3-K, LY294002, to assess the effects of inhibiting PI3-K on anoikis resistance of these cells. Addition of $25 \mu \mathrm{M}$ of LY294002 significantly increased anoikis fractions in pIRES-HMGA1.1 and pIRES-HMGA1.2 clones (Figure 3C). Treatment of parental MiaPaCa2 and empty pIRES-puro3 controls with LY294002 also inhibited anoikis resistance, although to lesser extent than for pIRES-HMGA1.1 and pIRES-HMGA1.2 clones. Second, infection of pIRES-HMGA1.1 and pIRES-HMGA1.2 clones with adenovirus expressing a dominant-negative Akt construct also significantly increased anoikis fractions in both HMGA1-overexpressing clones 

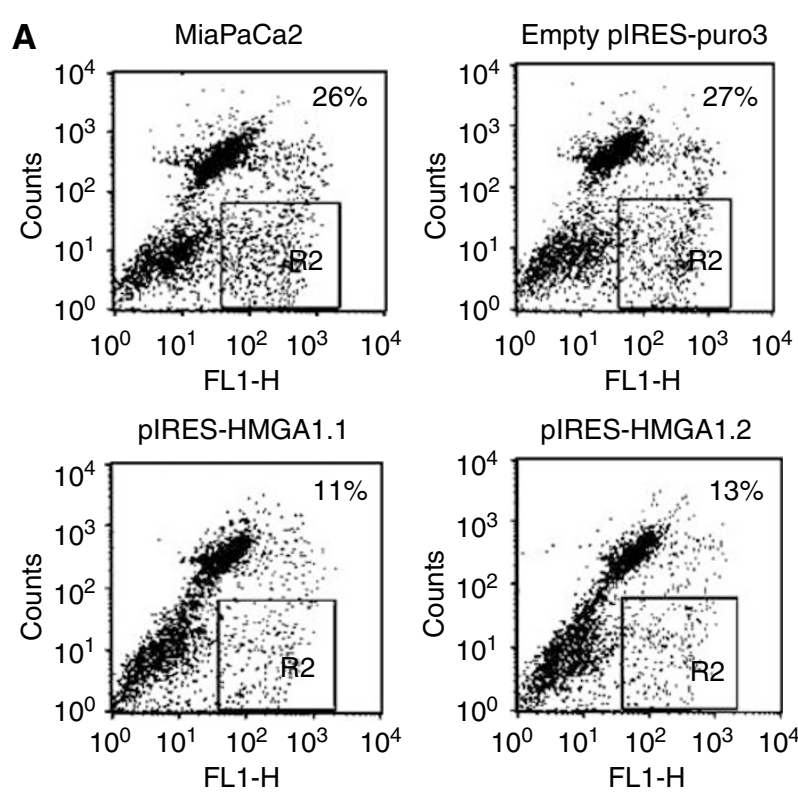

B

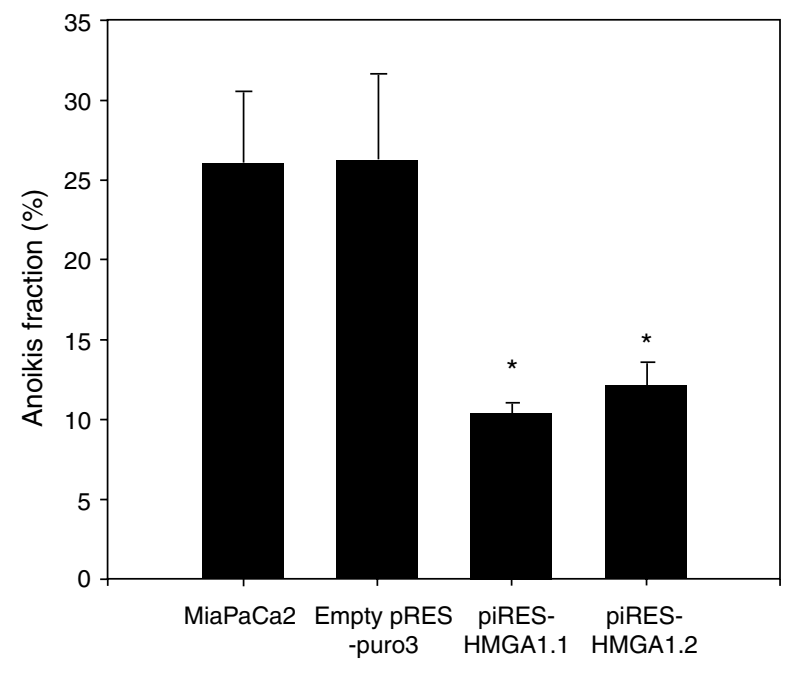

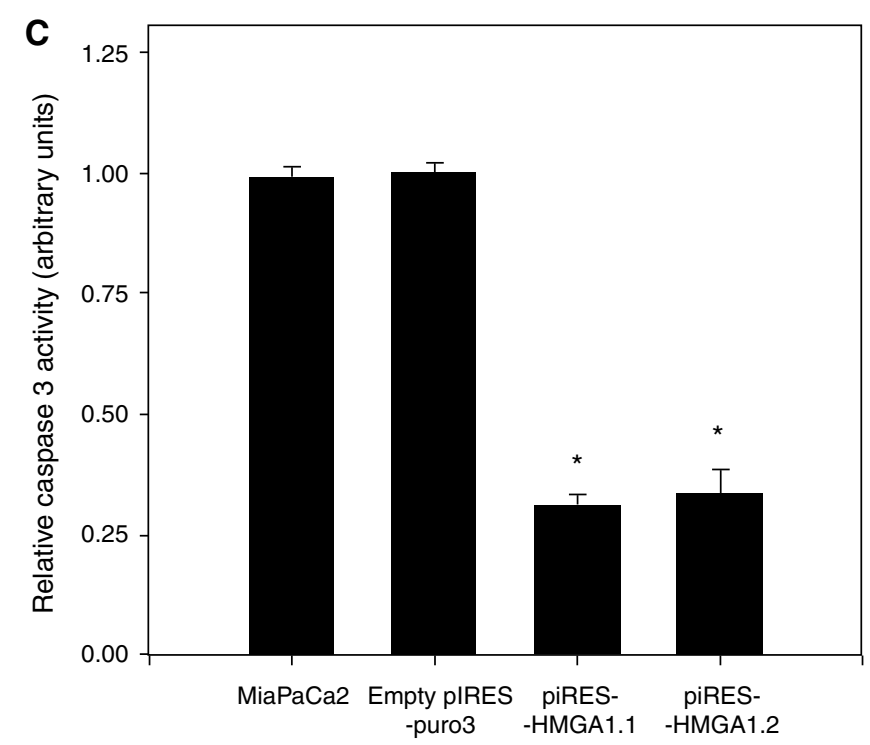

Figure 2 (A, B) Forced HMGAI overexpression protects MiaPaCa2 cells, which have low inherent expression of HMGAI, from anoikis. Representative flow cytometric images are shown with anoikis fractions highlighted in the inserted square (Figure 2A). Clones pIRES-HMGAI.I and pIRES-HMGAI.2 exhibited 2- to 2.5-fold reductions in anoikis fraction compared to parental MiaPaCa2 cells and pIRES-puro3 control stable transfectants (Figure 2B). $* P<0.05$ vs parental MiaPaCa2 cells or empty pIRES-puro3 transfectants. (C) HMGAI overexpression protects MiaPaCa2 cells from caspase-mediated anoikis. pIRES-HMGAI.I and pIRES-HMGAI.2 clones showed significant reductions in caspase 3 activity, compared to parental MiaPaCa2 cells and empty pIRES-puro3 transfectants, following induction of anoikis on polyHEMA plates for $18 \mathrm{~h}$. ${ }^{*} P<0.05$ vs parental MiaPaCa2 cells or empty pIRES-puro3 transfectants.

(Figure 3D). Parental MiaPaCa2 and empty pIRES-puro3 controls also exhibited increased anoikis fractions with infection of adenovirus expressing dominant-negative Akt construct, but to a lesser extent than the HMGA1-overexpressing clones. Taken together, these results suggest that HMGA1 overexpressioninduced anoikis resistance is dependent on PI3-K/Akt signalling.

\section{Targeted RNAi of HMGA1 in MiaPaCa2 and BxPC3 pancreatic adenocarcinoma cells increases susceptibility to anoikis}

Given the effects of HMGA1 overexpression on anoikis resistance in MiaPaCa2 cells, we asked if silencing of HMGA1 in the same cell line will have the reverse effects. In addition, we also selected BxPC3 pancreatic adenocarcinoma cell line for RNAi experiments as these cells have high levels of HMGA1 expression at baseline. In these lentivirus-mediated RNAi experiments, we developed pooled stable transfectants. Stable transfectants derived from infection with lentivirus developed from empty PLKO.1 and scramble shRNA transfer plasmids served as controls. We achieved at least $90 \%$ silencing of HMGA 1 expression in both MiaPaCa2 and $\mathrm{BxPC} 3$ cells (Figure 4A). Of note, neither HMGA1 overexpression nor silencing had any impact on lamin B expression (used to normalise for protein loading, Figures 1 and 4A). HMGA1 silencing was associated with significant increases in anoikis fractions in both cell lines (Figure 4B). 
A
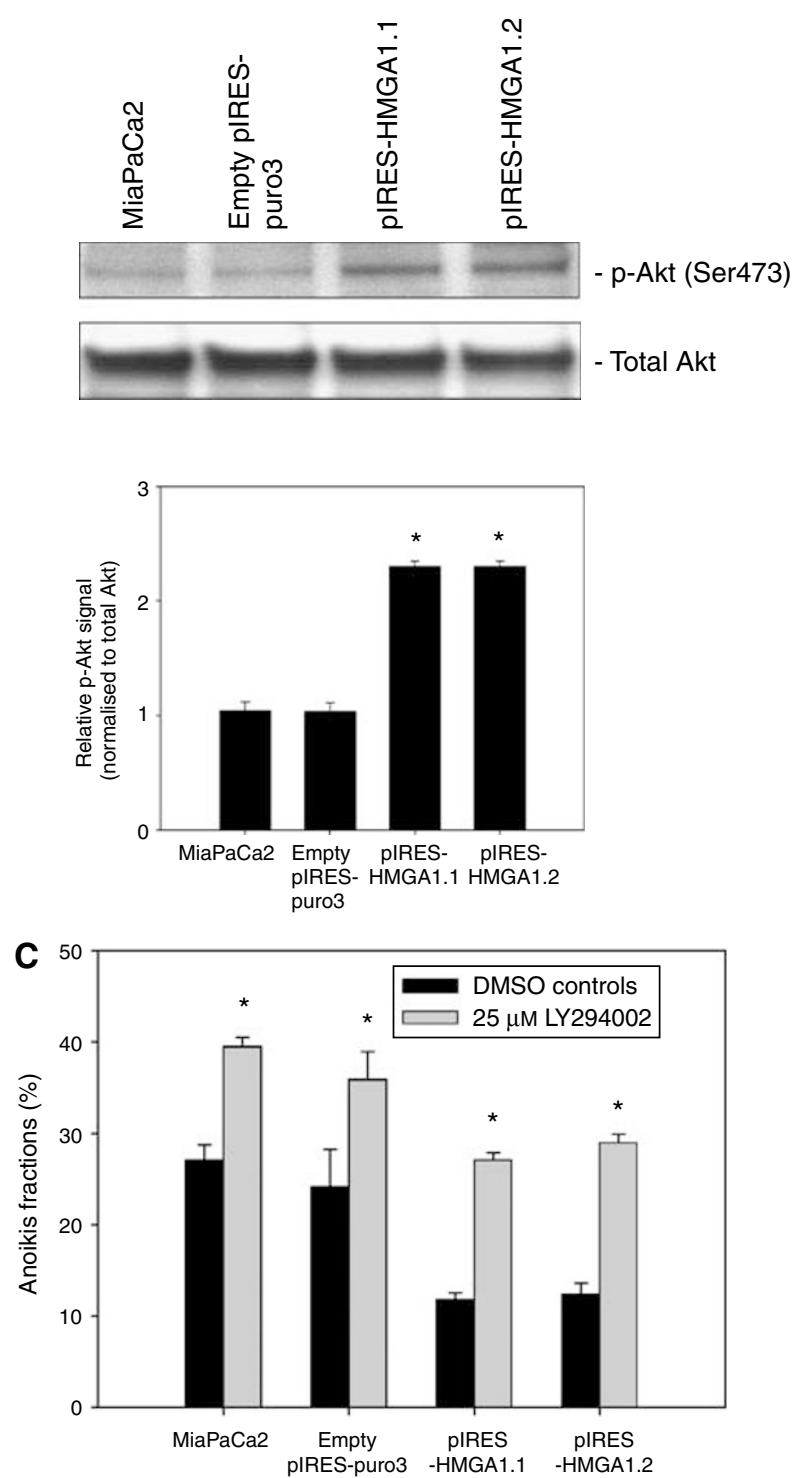

B


Figure 3 (A) Overexpression of HMGAI led to increased activation of Akt, as evident from increased levels of phospho-Akt (Ser473), a marker of Akt activation. Both pIRES-HMGAI.I and pIRES-HMGAI.2 clones exhibited a higher degree of Akt phosphorylation compared to control cells. There were no differences in the level of expression of total Akt with overexpression of HMGAI. $* P<0.05$ vs parental MiaPaCa2 cells or empty pIRES-puro3 transfectants. Blot shown is representative of three independent experiments. (B) Correspondingly, overexpression of HMGAI results in increased Akt kinase activities as determined by fluorometric real-time Akt kinase assays. Slope of Akt kinase activity curves indicates the levels of Akt kinase activity. Representative results of Akt kinase activity assay from three independent experiments are shown. pIRES-HMGAI.I and PIRES-HMGAI.2 clones showed steeper activity curve slopes and hence Akt kinase activities, when compared to empty pIRES-puro 3 controls. $* P<0.05$ vs empty pIRES-puro3 vector transfectants. (C) Anoikis resistance induced

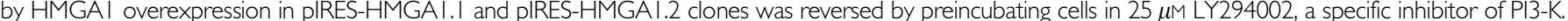
Inhibiting PI3-K resulted in increases in anoikis fractions in pIRES-HMGAI.I and pIRES-HMGAI.2 clones to levels similar to parental MiaPaCa2 and empty pIRESpuro 3 controls. Controls were cells treated with the DMSO vehicle. *P $<0.05$ vs DMSO controls. (D) Similarly, infection of pIRES-HMGAI.I and pIRES-HMGAI.2 clones with adenovirus carrying dominant-negative Akt I resulted in reversal of anoikis resistance with increases in anoikis fractions in both HMGAI-overexpressing clones. Controls were cells infected with adenovirus expressing an empty CMV promoter (Ad-CMV-null). *P $<0.05$ vs control adenovirus (Ad-CMV-null).

\section{Modulation of HMGA1 expression did not have an impact on growth characteristics of pancreatic adenocarcinoma cells}

Neither overexpression (Figure 5A) nor targeted suppression of HMGA1 expression (Figure 5B) had any impact on proliferation rates of pancreatic adenocarcinoma cells studied.

\section{DISCUSSION}

Pancreatic adenocarcinoma is associated with dismal prognosis, in large part resulting from metastatic disease, even in patients initially deemed to be surgically resectable. We have focused our efforts in studying the mechanisms underlying metastasis in 
A

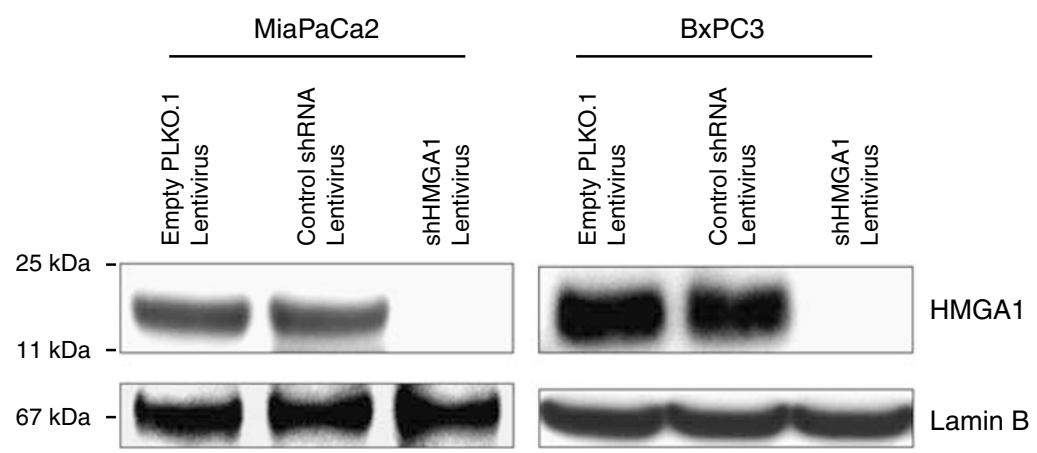

B
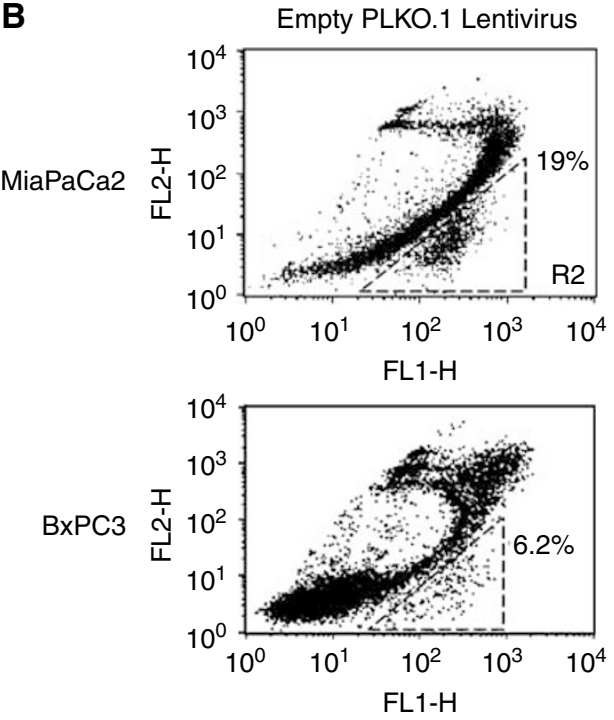
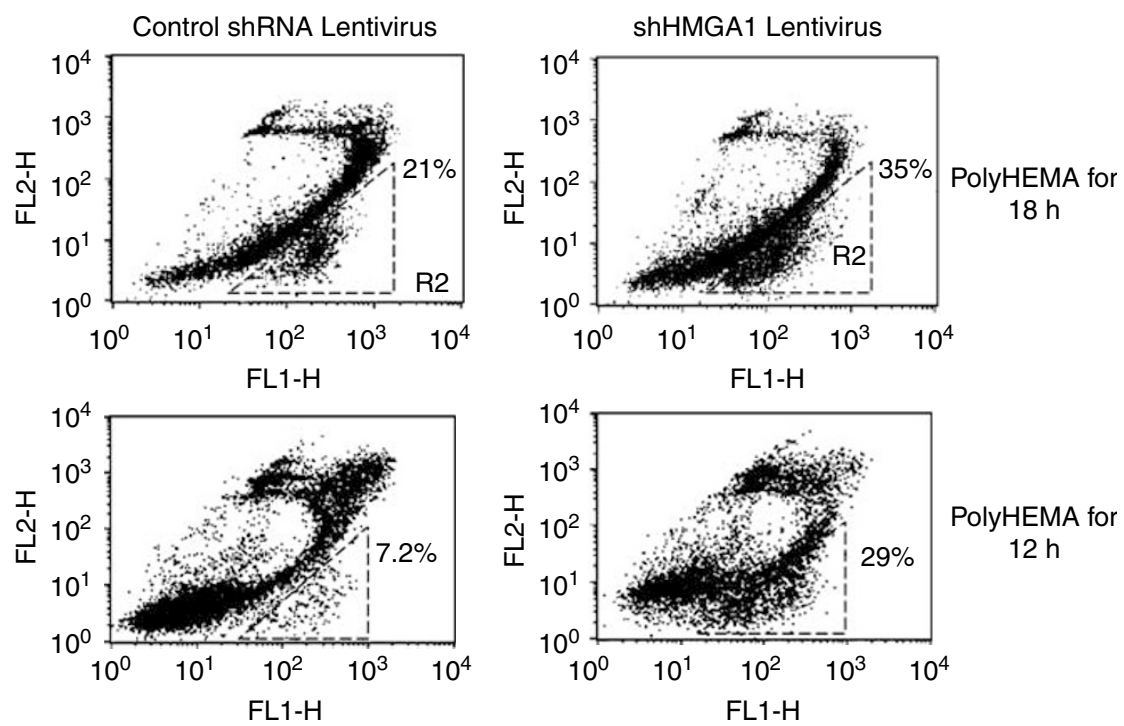



Figure 4 (A) Using lentivirus-mediated RNAi of HMGAI, we achieved up to 90\% silencing of HMGAI expression in both MiaPaCa2 and BxPC3 cell lines. A representative Western blot performed on nuclear extracts showing the degree of HMGAI silencing is shown. Controls were stable transfectants developed following infection with lentivirus expressing empty PLKO.I or scramble RNAi sequence. (B) Silencing of HMGAI promoted anoikis in both cell lines following culture in polyHEMA plates for 18 (for MiaPaCa2) and $12 \mathrm{~h}$ (for BxPC3). Representative images of flow cytometric analyses of anoikis fractions with apoptotic populations highlighted in triangles drawn are shown. Targeted suppression of HMGAI resulted in significant increases in anoikis fractions in both MiaPaCa2 and BxPC3 cells compared to empty PLKO.I and scramble RNAi-stable transfectants. *P<0.05 vs empty PLKO.I or scramble RNAi transfectants. 

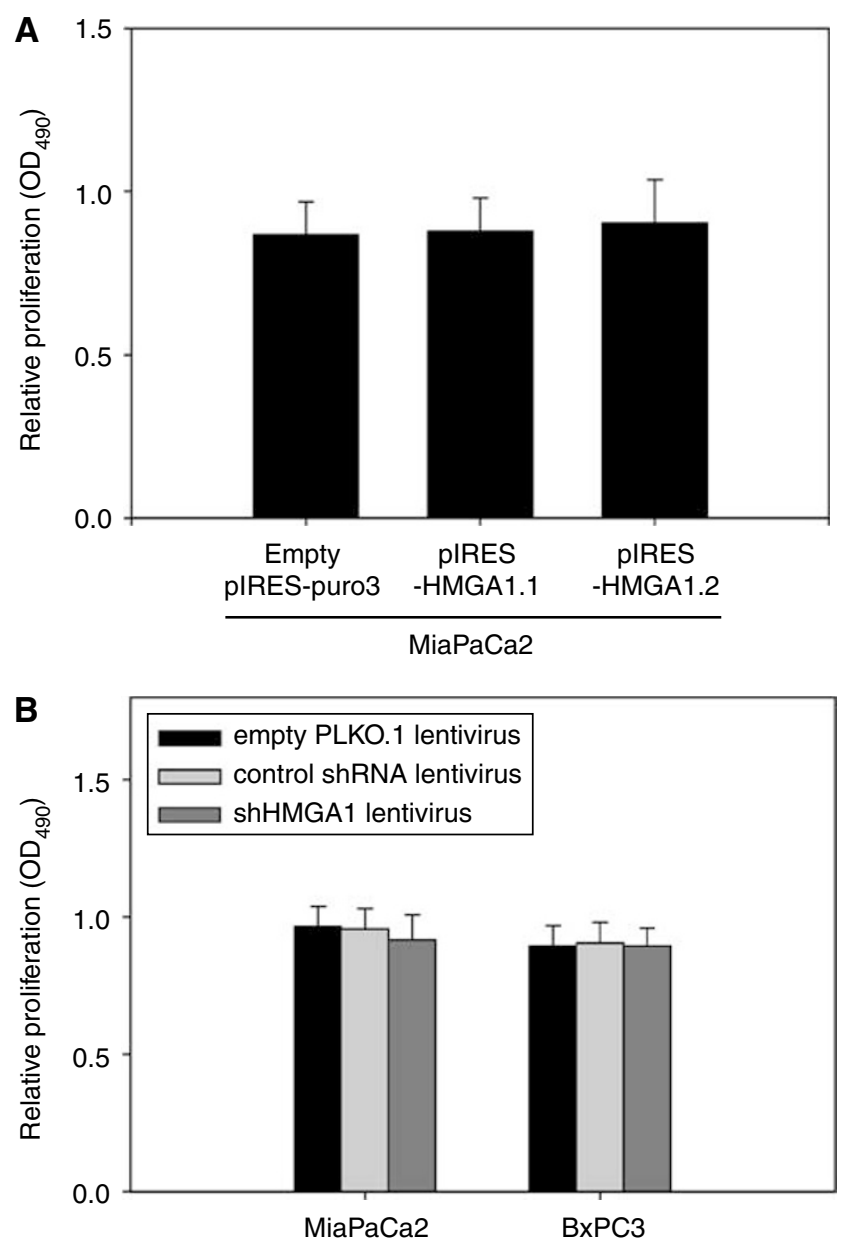

Figure 5 (A and $\mathbf{B}$ ) Cellular proliferation was quantified by MTS assay $48 \mathrm{~h}$ following seeding wells with $5 \times 10^{3}$ cells. Modulation of HMGAI expression did not affect cellular proliferation in monolayer culture. Values are mean \pm s.d. from triplicate experiments with 10 determinations per condition.

pancreatic adenocarcinoma, with the goal of rationally identifying molecular targets that can be exploited to inhibit this process. In our work, we have used anoikis resistance as an in vitro correlate of metastatic potential. In this study, we have shown that HMGA1 overexpression confers anoikis resistance to pancreatic adenocarcinoma cells by activating the prosurvival PI3-K/Akt signalling pathway. This is the first report describing a regulatory role of HMGA1 on Akt signalling in a cancer model.

Numerous reports have described HMGA1 overexpression to be prevalent in a wide range of human malignancies. Increasingly, tumoural HMGA1 expression status is reported to have prognostic value among patients with cancer (Sarhadi et al, 2006). Recently, data suggesting mechanisms by which HMGA1 may mediate cancer progression have begun to emerge. For example, HMGA1 proteins have been demonstrated to promote tumour progression and epithelial-mesenchymal transition in human breast epithelial cells (Reeves et al, 2001). In immortalised rat embryonic fibroblast Ratla cells, HMGA1 was found to be a c-Jun-target gene and its suppression by antisense methodology was found to reduce the ability of c-Jun-overexpressing cells to grow under anchorage-independent conditions (Hommura et al, 2004).

Although previous reports have implicated HMGA1 as having the capacity to promote tumourigenesis and anchorage-independent growth in normal epithelial cells (Reeves et al, 2001), no studies reported to date have examined specifically the role of HMGA1 in mediating anoikis resistance in the context of cancer cells. Our findings suggest that HMGA1 overexpression represents a molecular determinant of anoikis resistance in pancreatic adenocarcinoma cells. The biological significance of this finding relates to emerging understanding that anoikis resistance is a phenotypic hallmark of metastatic cancer cells (Chuma et al, 2004; Douma et al, 2004). Although the underlying mechanisms rendering anoikis resistance in cancer cells are incompletely understood, our findings provide evidence for a novel role for HMGA1 in mediating this process. Further, our findings provide a potential mechanism by which HMGA1 overexpression induces anoikis resistance: activation of the antiapoptotic PI3-K/Akt signalling pathway.

Description of regulatory roles for HMGA1 in the context of apoptosis is not without precedent. HMGA1 has been found to associate in vivo with p53 family members and inactivate their functions. As such, overexpression of HMGA1 may lead to suppression of p53-induced apoptosis and tumour-suppressing activity (Frasca et al, 2006). In addition, antisense-mediated suppression of HMGA1 expression in thyroid carcinoma and pancreatic adenocarcinoma cell lines has been reported to induce an apoptotic response (Scala et al, 2000; Trapasso et al, 2004). Our findings that HMGA1 overexpression results in constitutive activation of PI3-K/Akt pathway provide another mechanism through which HMGA1 mediates its antiapoptotic functions. HMGA1-dependent activation of Akt signalling is likely to protect cancer cells from broad array of proapoptotic stimuli, not just those related to anchorage deprivation. Indeed, we have recently reported that HMGA1 protects pancreatic adenocarcinoma cells from gemcitibine-induced apoptosis and in this context is a potential molecular determinant of chemoresistance in pancreatic cancer (Liau et al, 2006).

Our findings, taken together with those previously reported, provide a mechanistic basis for conceptualising the known correlations between HMGA1 expression and poor prognosis in cancer patients (Chiappetta et al, 2004). These findings also have obvious therapeutic implications. Future studies will need to address whether targeted therapies directed against HMGA1 will inhibit metastasis in pancreatic cancer.

\section{ACKNOWLEDGEMENTS}

S-S Liau is a receipt of the International Hepato-pancreatobiliary Association (IHPBA) Kenneth W Warren Fellowship, Pancreatic Society of Great Britain and Ireland Traveling Fellowship, Aid for Cancer Research Grant (USA) and Cancer Research UK Core Skills Bursary. This work was supported by NIH 1 RO1 CA114103 and American Cancer Society RSG-04221-01-CCE. We thank the technical assistance of Jan D Rounds.

\section{REFERENCES}

Abe N, Watanabe T, Masaki T, Mori T, Sugiyama M, Uchimura H, Fujioka Y, Chiappetta G, Fusco A, Atomi Y (2000) Pancreatic duct cell carcinomas express high levels of high mobility group $\mathrm{I}(\mathrm{Y})$ proteins. Cancer Res 60: 3117-3122
Balcerczak M, Pasz-Walczak G, Balcerczak E, Wojtylak M, Kordek R, Mirowski M (2003) HMGI(Y) gene expression in colorectal cancer: comparison with some histological typing, grading, and clinical staging. Pathol Res Pract 199: 641-646 
Berezovskaya O, Schimmer AD, Glinskii AB, Pinilla C, Hoffman RM, Reed JC, Glinsky GV (2005) Increased expression of apoptosis inhibitor protein XIAP contributes to anoikis resistance of circulating human prostate cancer metastasis precursor cells. Cancer Res 65: 2378-2386

Chang ZG, Yang LY, Wang W, Peng JX, Huang GW, Tao YM, Ding X (2005) Determination of high mobility group A1 (HMGA1) expression in hepatocellular carcinoma: a potential prognostic marker. Dig Dis Sci 50: $1764-1770$

Chiappetta G, Botti G, Monaco M, Pasquinelli R, Pentimalli F, Di Bonito M, D’Aiuto G, Fedele M, Iuliano R, Palmieri EA, Pierantoni GM, Giancotti V, Fusco A (2004) HMGA1 protein overexpression in human breast carcinomas: correlation with ErbB2 expression. Clin Cancer Res 10: $7637-7644$

Chuma M, Saeki N, Yamamoto Y, Ohta T, Asaka M, Hirohashi S, Sakamoto M (2004) Expression profiling in hepatocellular carcinoma with intrahepatic metastasis: identification of high-mobility group I(Y) protein as a molecular marker of hepatocellular carcinoma metastasis. Keio J Med 53: $90-97$

Czyz W, Balcerczak E, Jakubiak M, Pasieka Z, Kuzdak K, Mirowski M (2004) HMGI(Y) gene expression as a potential marker of thyroid follicular carcinoma. Langenbecks Arch Surg 389: 193-197

Donato G, Martinez Hoyos J, Amorosi A, Maltese L, Lavano A, Volpentesta G, Signorelli F, Pentimalli F, Pallante P, Ferraro G, Tucci L, Signorelli CD Viglietto G, Fusco A (2004) High mobility group A1 expression correlates with the histological grade of human glial tumors. Oncol Rep 11: $1209-1213$

Douma S, Van Laar T, Zevenhoven J, Meuwissen R, Van Garderen E, Peeper DS (2004) Suppression of anoikis and induction of metastasis by the neurotrophic receptor TrkB. Nature 430: 1034-1039

Frasca F, Rustighi A, Malaguarnera R, Altamura S, Vigneri P, Del Sal G, Giancotti V, Pezzino V, Vigneri R, Manfioletti G (2006) HMGA1 inhibits the function of p53 family members in thyroid cancer cells. Cancer Res 66: $2980-2989$

Friedmann M, Holth LT, Zoghbi HY, Reeves R (1993) Organization, inducible-expression and chromosome localization of the human HMGI(Y) nonhistone protein gene. Nucleic Acids Res 21: 4259-4267

Frisch SM, Francis H (1994) Disruption of epithelial cell-matrix interactions induces apoptosis. J Cell Biol 124: 619-626

Hommura F, Katabami M, Leaner VD, Donninger H, Sumter TF, Resar LM, Birrer MJ (2004) HMG-I/Y is a c-Jun/activator protein-1 target gene and is necessary for c-Jun-induced anchorage-independent growth in Ratla cells. Mol Cancer Res 2: 305-314

Jemal A, Siegel R, Ward E, Murray T, Xu J, Smigal C, Thun MJ (2006) Cancer statistics, 2006. CA Cancer J Clin 56: 106-130

Liau S-S, Ashley SW, Whang EE (2006) Lentivirus-mediated RNA interference of HMGA1 promotes chemosensitivity to gemcitabine in pancreatic adenocarcinoma. J Gastrointest Surg 10: 1254-1263

Moore SM, Rintoul RC, Walker TR, Chilvers ER, Haslett C, Sethi T (1998) The presence of a constitutively active phosphoinositide 3-kinase in small cell lung cancer cells mediates anchorage-independent proliferation via a protein kinase B and p70s6k-dependent pathway. Cancer Res 58: $5239-5247$

Nguyen KT, Zong CS, Uttamsingh S, Sachdev P, Bhanot M, Le MT, Chan JL, Wang LH (2002) The role of phosphatidylinositol 3-kinase, rho family GTPases, and STAT3 in Ros-induced cell transformation. J Biol Chem 277: $11107-11115$

Reeves R, Nissen MS (1990) The A.T-DNA-binding domain of mammalian high mobility group I chromosomal proteins. A novel peptide motif for recognizing DNA structure. J Biol Chem 265: 8573-8582

Reeves R, Edberg DD, Li Y (2001) Architectural transcription factor HMGI(Y) promotes tumor progression and mesenchymal transition of human epithelial cells. Mol Cell Biol 21: 575-594

Sarbassov DD, Guertin DA, Ali SM, Sabatini DM (2005) Phosphorylation and regulation of $\mathrm{Akt} / \mathrm{PKB}$ by the rictor-mTOR complex. Science 307: $1098-1101$

Sarhadi VK, Wikman H, Salmenkivi K, Kuosma E, Sioris T, Salo J, Karjalainen A, Knuutila S, Anttila S (2006) Increased expression of high mobility group A proteins in lung cancer. J Pathol 209: 206-212

Scala S, Portella G, Fedele M, Chiappetta G, Fusco A (2000) Adenovirusmediated suppression of $\mathrm{HMGI}(\mathrm{Y})$ protein synthesis as potential therapy of human malignant neoplasias. Proc Natl Acad Sci USA 97: $4256-4261$

Stewart SA, Dykxhoorn DM, Palliser D, Mizuno H, Yu EY, An DS, Sabatini DM, Chen IS, Hahn WC, Sharp PA, Weinberg RA, Novina CD (2003) Lentivirus-delivered stable gene silencing by RNAi in primary cells. RNA 9: $493-501$

Tamimi Y, van der Poel H, Karthaus H, Debruyne FS, Schalken JA (1996) A retrospective study of high mobility group protein $\mathrm{I}(\mathrm{Y})$ as progression marker for prostate cancer determined by in situ hybridization. $\mathrm{Br} \mathrm{J}$ Cancer 74: $573-578$

Thanos D, Maniatis T (1995) Virus induction of human IFN beta gene expression requires the assembly of an enhanceosome. Cell 83: $1091-1100$

Trapasso F, Sarti M, Cesari R, Yendamuri S, Dumon KR, Aqeilan RI, Pentimalli F, Infante L, Alder H, Abe N, Watanabe T, Viglietto G, Croce CM, Fusco A (2004) Therapy of human pancreatic carcinoma based on suppression of HMGA1 protein synthesis in preclinical models. Cancer Gene Ther 11: 633-641

$\mathrm{Xu}$ Y, Sumter TF, Bhattacharya R, Tesfaye A, Fuchs EJ, Wood LJ, Huso DL, Resar LM (2004) The HMG-I oncogene causes highly penetrant, aggressive lymphoid malignancy in transgenic mice and is overexpressed in human leukemia. Cancer Res 64: 3371-3375

Yawata A, Adachi M, Okuda H, Naishiro Y, Takamura T, Hareyama M, Takayama S, Reed JC, Imai K (1998) Prolonged cell survival enhances peritoneal dissemination of gastric cancer cells. Oncogene 16: $2681-2686$

Zhu Z, Sanchez-Sweatman O, Huang X, Wiltrout R, Khokha R, Zhao Q, Gorelik E (2001) Anoikis and metastatic potential of cloudman S91 melanoma cells. Cancer Res 61: 1707-1716 